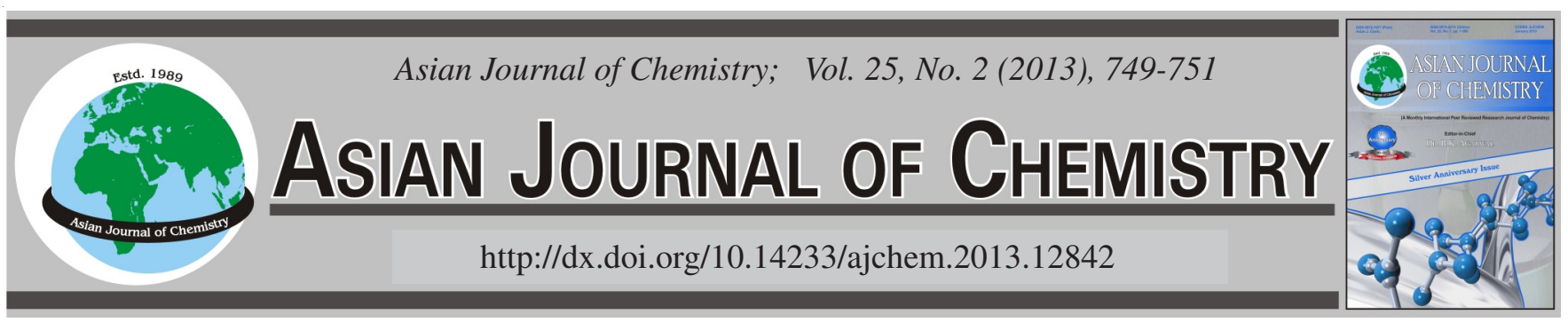

\title{
Extraction of Cantharidin from Mylabris phalerata Pallas with Compound Enzyme and HPLC Analysis
}

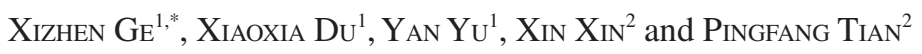 \\ ${ }^{1}$ Biochemical Engineering College of Beijing Union University, Beijing 100023, P.R. China \\ ${ }^{2}$ College of Life Science and Technology, Beijing University of Chemical Technology, Beijing 100029, P.R. China \\ *Corresponding author: Tel: +86 10 52072020, E-mail: gexizhen@163.com
}

(Received: 11 October 2011;

Accepted: 20 August 2012)

AJC-11969

Cantharidin is a monoterpene anhydride released from beetle Mylabris phalerata Pallas or Mylabris cichorii Linnaeus as a defensive
substance showing versatile pharmacological activities especially anticancer. Now efficient extraction methods for cantharidin have been
established so far. Here, four extraction methods, including hydrochloric acid, NaOH solution, mixed extraction and compound enzyme
(cellulase and pectinase) methods were compared with traditional Chinese pharmacopoeia extraction method. A quantitative HPLC
method was developed for the estimation of cantharidin in Mylabris phalerata extract. The compound enzyme method was revealed to
present the highest yield of cantharidin among these methods, followed in order by hydrochloric acid method, mixed extraction method,
Chinese pharmacopoeia method and NaOH solution method. The HPLC conditions comprise: diamonsil $\mathrm{C}_{18}(250 \mathrm{~mm} \times 4.6 \mathrm{~mm}, 5 \mu \mathrm{m})$,
flow rate of $1.0 \mathrm{~mL} / \mathrm{min}$, detection wavelength of $273 \mathrm{~nm}$, column temperature at $25^{\circ} \mathrm{C}$, mobile phase with acetonitrile: water $=40: 60$.
Under these conditions, cantharidin could be well extracted from Mylabris phalerata.

Key Words: Cantharidin, Mylabris phalerata Pallas, Extraction, Cellulase, Pectinase.

\section{INTRODUCTION}

Cantharidin or 2,3-dimethyl-7-oxabicyclo[1,2,2]heptane2,3-dicarboxylic anhydride is a monoterpene anhydride released from beetle Mylabris phalerata Pallas or Mylabris cichorii Linnaeus as a defensive substance. Of diverse insects, only $M$. phalerata and $M$. cichorii have been so far recognized as cantharidin producer. Cantharidin has been employed to cure abdominal lumps, amenorrhea, stubborn dermatitis, scrofula, malignant sore, as well as carbuncle. This record goes back to the ancient medical book of China" Shen Nong's Materia Medica" in Ming dynasty ${ }^{1}$ and $M$. phalerata or $M$. cichorii were indexed by State Pharmacopoeia of the People's Republic of China ${ }^{2}$. Nowadays, cantharidin has been centered as an antitumor agent to treat hepatocirrhosis, gastric carcinoma, breast cancer, hepatogenic cancer, hepatitis carrier, esophageal carcinoma and lung cancer in clinic $^{3-6}$. Unfortunately, the current chloroform and acid extraction methods usually lead to considerable yield $\operatorname{loss}^{7}$, therefore, there is an urgent demand for efficient extraction methods. Inspired by the extraction of flavonoids from Ginkgo biloba leaves using compound enzyme ${ }^{8}$, whereby high yield of active ingredients were achieved because cellulase and pectinase degraded cell wall, in this present study, we employed cellulose and pectinase to extract cantharidin from $M$. phalerata. Apart from comparison with other extraction methods, a reliable analysis method was also required.

\section{EXPERIMENTAL}

Mylabris phalerata was purchased from Anguo Medical Market in Hebei Province of China, voucher specimens of the beetles were deposited in Biochemical Engineering College of Beijing Union University. Cantharidin was purchased from Nanjing Ze Long Medical Technology Company Limited (98\% purity). Cellulose (activity of $6 \times 10^{5} \mathrm{U} / \mathrm{g}$ ) and pectinase (activity of $8 \times 10^{5} \mathrm{U} / \mathrm{g}$ ) were purchased from Sunson Group, Beijing, China. All chemicals were of analytical or chromatography grade.

Extraction methods: Beetle materials (100 g for each method) were pulverized to 30 mesh and the following procedures were operated.

Chinese pharmacopoeia method: Mylabris phalerata was shaken with chloroform of $2000 \mathrm{~mL}$ for $15 \mathrm{~min}$, soaked with chloroform for $6 \mathrm{~h}$ at room temperature, filtrated, the fluid was collected and evaporated in a rotary evaporator, followed by a constant chloroform volume to fill the concentrated extracts. 


\section{Mixed extraction method (chloroform, $\mathrm{HCl}$, ethanol):}

The materials were extracted with $750 \mathrm{~mL}$ of mixed solution (chloroform: $\mathrm{HCl}$ :ethanol $=1: 1: 1$ ) for $23 \mathrm{~h}$ in a $63{ }^{\circ} \mathrm{C}$ water bath pot, the extraction was filtrated at once, the residue was extracted twice with above mentioned mixed solution. The filtered fluid was combined, evaporated in a rotary evaporator, the extract was dissolved with mixed solution (water:chloroform $=1: 1$ ), the organic phase was evaporated and dissolved with the mixed solution (petroleum ether:ethanol $=1: 1$ ) for detection.

Enzyme extraction method (cellulase, pectinase): Mylabris phalerata were mixed with compound enzyme (cellulose $8 \mathrm{~g}$, pectinase $16 \mathrm{~g}$ ) based on pre-experiment, the $\mathrm{pH}$ of water solution was adjusted to 5.6 with citric acid, extracted at $40 \pm 2{ }^{\circ} \mathrm{C}$ for $2 \mathrm{~h}$ in a water bath pot, the residue was extracted as described before.

Extraction with hydrochloric acid: $600 \mathrm{~mL}$ chloroform, $400 \mathrm{~mL}$ acetone and $20 \mathrm{~mL}$ hydrochloric acid were added to Mylabris phalerata for reflux extraction of $12 \mathrm{~h}$, filtrated, the fluid was collected and evaporated in a rotary evaporator, followed by a constant chloroform volume to fill the concentrated extract for detection.

Extraction with $\mathrm{NaOH}$ solution: The materials were soaked with $600 \mathrm{~mL}$ of $\mathrm{NaOH}$ solution $(0.2 \mathrm{~mol} / \mathrm{L})$ for $0.5 \mathrm{~h}$, shook at $80^{\circ} \mathrm{C}$ for $2 \mathrm{~h}$. After centrifugation at $3000 \mathrm{~g} / \mathrm{min}$ for $20 \mathrm{~min}$, the supernatants were collected and the $\mathrm{pH}$ was adjusted to 1 , followed by a chloroform extraction, the organic phase was evaporated in a rotary evaporator, a constant chloroform volume was filled for detection.

TLC analysis: Extracts from Mylabris phalerata were respectively loaded to a silica gel plate $\left(10 \mathrm{~cm} \times 20 \mathrm{~cm}, \mathrm{GF}_{254}\right.$, Taizhou Si-Jia Biochemical Plastic Company, China) and developed with mobile phase of chloroform:acetone $=49: 1$ (v/v), $0.1 \%$ bromocresol green alcohol solution was sprayed, heated, yellow spots appeared.

HPLC detection and analysis: To quantify the cantharidin in extracts, HPLC analytical parameters including mobile phase, separation column, temperature, flow rate were explored. Consequently, the optimized chromatographic condition was established as follows: Preparative HPLC: Shimadzu, analytical HPLC, LC-10AT vp HPLC pump, CTO-10AS vp thermostated column compartment, SPD-10A vp detector and controller. Injection volume of all sample and standard solutions was 20 $\mu \mathrm{L}$. The cantharidin was calculated according to the standard curve. The increase rate (content ${ }_{x}$ compared with the pharmacopoeia method, content ${ }_{\mathrm{ph}}$ ) was calculated according to the following formula:

Increase rate $(\%)=\left(\right.$ content $_{\mathrm{x}}-$ content $\left._{\mathrm{ph}}\right) /$ content $_{\mathrm{ph}} \times 100(\%)$

\section{RESULTS AND DISCUSSION}

TLC results: TLC results for the extracts by five methods were shown in Fig. 1. The cantharidin was confirmed at $R_{f}$ 0.628 for each method. Much more spots were shown in enzyme extraction method, implying the generation of new substance when cellulose and pectinase were employed to degrade $M$. phalerata. This finding is coincided with the following HPLC result (Fig. 3).

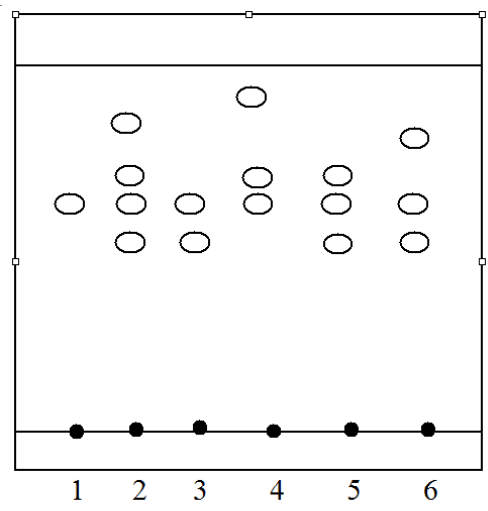

Fig. 1. TLC analysis for enzymatic and other methods. (1. Cantharidin; 2. Enzyme extraction solution; 3. Hydrochloric acid extraction solution; 4. NaOH extraction solution; 5. Mixed extraction solution; 6. Pharmacopoeia extraction solution)

HPLC analysis of cantharidin in extract: Considering gas chromatography had ever been used to determine cantharidine $e^{9,10}$, in the present work, gas chromatography was used to determine the cantharidin in extract. However, we failed to get an appropriate condition. For this reason, HPLC was alternatively used to identify cantharidin in the extract. Two kinds of chromatogram column PLatisil ODS and diamonsil $\mathrm{C}_{18}$ (4.6 mm $\times 250 \mathrm{~mm}, 5 \mu \mathrm{m}$, DIKMA, American), different wavelength $(230,260,273 \mathrm{~nm})$, as well as three mobile phase systems (water:methanol; water:acetonitrile: formic acid; acetonitrile:water) were tried. To achieve better chromatogram, different flow rate $(0.8,0.6$ and $1.0 \mathrm{~mL} / \mathrm{min})$ and temperature $\left(25,30\right.$ and $\left.35^{\circ} \mathrm{C}\right)$ were also tried. At last, the optimum HPLC conditions were listed as follows: Diamonsil $\mathrm{C}_{18}(250 \mathrm{~mm} \times$ $4.6 \mathrm{~mm}, 5 \mu \mathrm{m}$ ); the flow rate was $1.0 \mathrm{~mL} / \mathrm{min}$; detection wavelength is $273 \mathrm{~nm}$; column temperature was maintained at $25^{\circ} \mathrm{C}$; mobile phase was acetonitrile: water $=40: 60$. Under these conditions, cantharidine could be well separated (Figs. 2 and 3$)$.

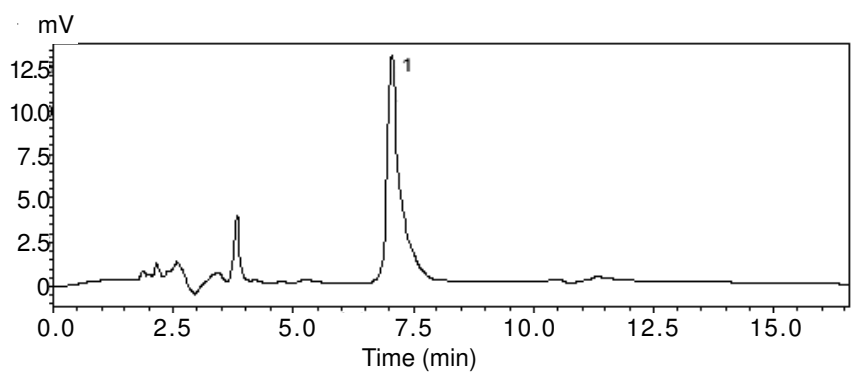

Fig. 2. Chromatogram analysis of cantharidin standard (1= cantharidin)

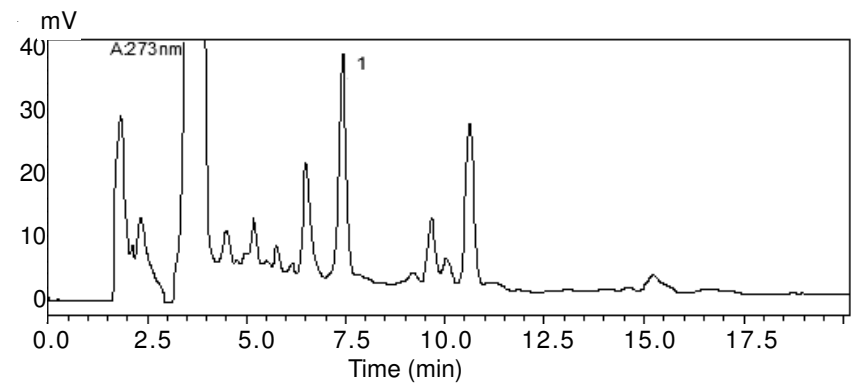

Fig. 3. Chromatogram analysis of Mylabris phalerata Pallas extraction (1 = cantharidin) 
Standard curve of cantharidin: Cantharidin of $10 \mathrm{mg}$ was accurately weighed and added to a $10 \mathrm{~mL}$ volumetric flask, dissolved in $5 \mathrm{~mL}$ chloroform and the solution was diluted to $10 \mathrm{~mL}$ with the same solvent. The retention time of standard cantharidin was $7.032 \mathrm{~min}$. The working calibration curve based on standard solutions showed good linearity. The standard curve of cantharidin was

$$
\mathrm{Y}=196707 \mathrm{X}+23419\left(\mathrm{R}^{2}=0.9998, \mathrm{n}=8\right)
$$

Comparison of extraction methods: Total cantharidin for each method was shown in Table-1, cantharidin was increased when sample was treated with combined enzymes. The total extraction yield of cantharidin was $1.327 \mathrm{mg} / \mathrm{mL}$, which ranked the highest among these methods. Compared with Chinese parmacopoeia extraction method $(0.461 \mathrm{mg} / \mathrm{mL})$, the increase rate was $187.85 \%$ ( $c a .3$ folds). For mixed extraction method, the total cantharidin was $0.593 \mathrm{mg} / \mathrm{mL}$, which was also higher than Chinese parmacopoeia extraction method (increase rate was $16.92 \%$ ). Similarly, hydrochloric acid extraction method presented total cantharidin of 0.704 $\mathrm{mg} / \mathrm{mL}$, with increase rate of $52.71 \%$ compared with Chinese parmacopoeia method. Conversely, $\mathrm{NaOH}$ solution method led to lower cantharidin content $(0.230 \mathrm{mg} / \mathrm{mL})$. For acid and alkali methods, the former presented higher cantharidin than the latter, because cantharidin was an anhydride which might bind $\mathrm{Na}, \mathrm{Mg}$ or other metal ions to form sodium salt or magnesium salt. In acidic environment, cantharidin would dissociate from the main conjugated body, thereby resulted in higher yield of cantharidin. Clearly, enzyme extraction method was suitable for extraction of cantharidin from M. phalerata. It might be attributed to cellulose and pectinase which degraded cell wall. In fact, similar conclusion has been reported by Chen et $a{ }^{8}{ }^{8}$ and in-depth study was needed to investigate the adaptability in large-scale industry.

\begin{tabular}{lcc}
\multicolumn{3}{c}{ TABLE-1 } \\
EFFECT OF DIFFERENT EXTRACTION \\
METHODS ON CANTHARIDIN CONTENT \\
\hline \multicolumn{1}{c}{ Extraction methods } & $\begin{array}{c}\text { Contents } \\
(\mathrm{mg} / \mathrm{mL})\end{array}$ & $\begin{array}{c}\text { Increase } \\
\text { rate }(\%)\end{array}$ \\
\hline Mixed extraction method & 0.539 & 16.92 \\
Enzyme extraction method & 1.327 & 187.85 \\
Extracting with hydrochloric acid & 0.704 & 52.71 \\
Extracting with NaOH solution & 0.230 & -50.11 \\
Chinese parmacopoeia extraction method & 0.461 & - \\
\hline
\end{tabular}

\section{Conclusion}

Two major conclusions could be drawn from this study: (i) Of the extraction methods, enzyme extraction method was found to be simple, easy to operate, benign to the environment and advantageous for the highest yield of cantharidin, followed in turn by hydrochloric acid extraction, mixed extraction method, Chinese pharmacopoeia method and $\mathrm{NaOH}$ solution method; (ii) HPLC analysis method was suitable for determining cantharidin, the optimum conditions comprise: diamonsil $\mathrm{C}_{18}(250 \mathrm{~mm} \times 4.6 \mathrm{~mm}, 5 \mu \mathrm{m})$, flow rate of $1.0 \mathrm{~mL} /$ min, detection wavelength of $273 \mathrm{~nm}$, column temperature at $25^{\circ} \mathrm{C}$, mobile phase of acetonitrile: water $=40: 60$.

\section{ACKNOWLEDGEMENTS}

This study was supported by a grant from Beijing Municipal Education Commission of the P.R. China (KM200911417011).

\section{REFERENCES}

1. G.S. Wang, J. Ethnopharmacol., 26, 147 (1989).

2. Chinese Pharmacopoeia Committee, State Pharmacopoeia of the People's Republic of China [S], Beijing: Chemical Industry Press, p. 233 (2005)

3. V. Bertini, M. Calderone, C. Fragai and E. Talluri, J. Med. Chem., 52, 4838 (2009).

4. O.D. Laerum and O.H. Iversen, Cancer Res., 32, 1463 (1972).

5. K. Bonness, I.V. Aragon, B. Rutland, S. Ofori-Acquah, N.M. Dean and R.E. Honkanen, Mol. Cancer Ther., 5, 2727 (2006).

6. D. Liu and Z. Chen, Anticancer Agents Med Chem., 9, 392 (2009).

7. Q. Liu, J.W. Chen, X. Li and B.C. Cai, J. Hainan Med. Coll., 17, 582 (2011).

8. S. Chen, X.H. Xing, J.J. Huang and M.S. Xu, Enzyme Microbiol. Technol., 48, 100 (2011).

9. A. Mehdinia, M. Asiabi, A. Jabbari and S.M. Abtahi, J. Chromatogr. B, 879, 2897 (2011)

10. C.M. Wei, Y. Teng, B.J. Wang, X.M. Zhang, G.Y. Yuan, X.Y. Liu, R. Li and R.C. Guo, J. Chromatogr. B, 879, 1741 (2011). 